\title{
A Comparative Study of Analyzing Software Reliability with Order Statistics Approach Using ANOM
}

\author{
Kotte Sandeep $^{1}$, Mekhala Sridevi Sameera ${ }^{2}$, R Satya Prasad ${ }^{3}$, GangadharaRao Kancharla ${ }^{4}$ \\ ${ }^{1}$ Assistant Professor, Dept of CSE, Dhanekula Institute of Engineering \& Technology, Vijayawada, A.P, India, \\ kottesandeep@gmail.com \\ ${ }^{2}$ Research Scholar, Dept of CSE, Acharya Nagarjuna University, Guntur, A.P, India, \\ mekala.sameera@gmail.com \\ ${ }^{3}$ Professor, Dept of CSE, Acharya Nagarjuna University, Guntur, A.P, India, profrsp@ gmail.com \\ ${ }^{4}$ Professor, Dept of CSE, Acharya Nagarjuna University, Guntur, A.P, India, kancherla123@gmail.com
}

\begin{abstract}
Software reliability is characterized as the probability that a product framework with no disappointment happening in a determined time on specified working conditions. Assessing software reliability and in this manner, keeping up quality during development and utilization of software is most significant, as software is being used in all domains alongside safety and non-security frameworks. Analysis of means (ANOM) can be applied to forecast software failures also, in this way contribute significantly to the improvement of software reliability. In this paper, we compared two models developed by us to analyze and assess software reliability using ANOM. The two models are based on Logarithmic Poisson Execution Time Model (LPETM) and GO model.
\end{abstract}

Key words: Order statistics, Analysis of means (ANOM), LPETM, GO, MLE, NHPP, Lower Decision Line (LDL), Upper Decision Line (UDL), Central Decision Line (CDL).

\section{INTRODUCTION}

Nowadays, computers are used in numerous areas and applications. In developing and testing new software products, software reliability assessment is progressively significant. Prior to releasing the product into the market, the newly developed software is tested thoroughly to identify errors. New errors may creep in when the distinguished errors are expelled during debugging. The failure costs will be high if the product with errors is released into the market. In this paper reliability is assessed by applying ANOM on order statistics failure data [3], [4].

Software reliability represents a client perspective on software quality. It relates legitimately to activity instead of the design of the program, and subsequently it is dynamic rather than static. Consequently, programming dependability is keen on disappointments happening and not shortcomings in a program. Unwavering quality measures are significantly more valuable than shortcoming measures.

In this paper, we compared two control mechanism developed by us to analyze and assess software reliability using ANOM. The two-control mechanism is based on time between failure observations using Logarithmic Poisson Execution Time Model (LPETM) and GO model.

\section{MODELS DESCRIPTION AND PARAMETER ESTIMATION}

Estimation of parameters is very influential in foreseeing the software reliability. After finishing up the analytical solution for the mean value function $\mathrm{m}(\mathrm{t})$ for the specific model, the MLE method is enforced for accomplishing the parameter estimation. The intension of MLE is to determine the parameters that magnify the probability of the fragment data. They yield estimators with good statistical factors. MLE techniques are flexible, adaptable and can be utilized to distinct models. To assess the software reliability, the unknown parameters ' $a$ ' and ' $b$ ' is to be treasured and they are to be anticipated utilizing the failure data of the software fragment data [1], [2].

Let ' $n$ ' be the time instances where the first, second,....Kth faults in the software are encountered. If Tk is the total time of the Kth failure, 'tk' is an observation of random variable Tk and ' $n$ ' such similar failures are successively recorded. The combined probability of such failure time handles $\mathrm{t} 1, \mathrm{t} 2, \ldots \ldots \ldots . \mathrm{tn}$ is given by the Likelihood function as

$\mathrm{L}=\mathrm{e}^{-\mathrm{m}\left(\mathrm{t}_{\mathrm{I}} !\right.} \cdot \prod_{\mathrm{R}=1}^{\mathrm{n}} \mathrm{m}^{\prime}\left(\mathrm{t}_{\mathrm{k}}\right)$

The logarithmic application of the equation (1) would result a $\log$ likelihood function and is given in equation (2).

$\log L=\sum_{i=1}^{n} \log [\lambda(t)]-m\left(t_{k}\right)^{r}$ 
Kotte Sandeep et al., International Journal of Emerging Trends in Engineering Research, 8(9), September 2020, 4894 - 4899

The MLE is highlighted to maximize $\mathrm{L}$ and estimate the values of ' $a$ ' and ' $b$ '. The process to maximize is by applying partial derivation with respective to the unknown variables and equate to zero to obtain a close form for the required variable. If the closed form is not destined, then the variable can be evaluated using Newton Raphson Method. In this manner ' $a$ ' and ' $b$ ' would be solutions of the equations [9].

$\frac{\partial \log L}{\partial a}=0, \frac{\partial \log L}{\partial b}=0 \frac{\partial^{2} \log L}{\partial b^{2}}=0$

\subsection{LOGARITHMIC POISSON EXECUTION TIME MODEL (LPETM)}

The mean value function $\mathrm{m}(\mathrm{t})$ of LPETM is given

$m(t)=a \log (1+b t)$

To get $m(t)$ value for rth order statistics, take $m(t)$ to the power ' $\mathrm{r}$ '

$m(t)^{r}=a^{r} \cdot \log (1+b t)^{r}$

The failure intensity function is

$$
\begin{aligned}
& \lambda(\mathrm{t})-\frac{\partial}{\partial t} \mathrm{~m}(\mathrm{t})^{r} \\
& \lambda(\mathrm{t})=\frac{\mathrm{a}^{\mathrm{r}} \cdot \mathrm{r} \cdot \mathrm{b}}{(1+\mathrm{bt})}
\end{aligned}
$$

Implanting the equations for $m(t)^{\gamma^{n}}, \lambda(\mathrm{t})$ given by (4) \& (6) equation in equation 2 and executing the aforementioned process and with the aid of few combined simplifications.

$a^{r}=\frac{n}{\log \left(1+b t_{k}\right)^{r}}$

$\mathrm{g}(\mathrm{b})=\frac{\mathrm{n}}{\mathrm{b}}-\sum_{i=1}^{n} \frac{t_{i}}{\left(1+b t_{i}\right)}-\frac{r \cdot t_{k}}{\left(1+b t_{k}\right) \log \left(1+b t_{k}\right)}$

$g^{1}(b)--\frac{n}{b^{2}}+\sum_{i=1}^{n} \frac{t_{i}^{2}}{\left(1+b t_{i}\right)^{2}}+r\left[\frac{t_{k}{ }^{2}}{\left(1+b t_{k}\right)^{2} \cdot \log \left(1+b t_{k}\right)}+\frac{t_{k}^{2}}{\left(1+b t_{k}\right)^{2} *\left(\log \left(1+b t_{k}\right)^{2}\right.}\right]$

We get closure form for variable ' $a$ ' in terms of ' $b$ '. Iterative Newton-Raphson method is used to solving the equations (7), (8), (9) in order to get the approximated a \& b value for the given set of failure data [9].

\subsection{GO MODEL}

The mean value function $\mathrm{m}(\mathrm{t})$ of GO Model is given

$m(t)=a\left(1-e^{-b t}\right)$
To get $m(t)$ value for rth order statistics, take $m(t)$ to the power ' $\mathrm{r}$ '

$m(t)^{r}=a^{r} \cdot\left(1-e^{-b t}\right)^{r}$

The failure intensity function is

$\lambda(t)=a^{r} \cdot b \cdot e^{-b t} \cdot r \cdot\left(1-e^{-b r}\right)^{r-1}$

Implanting the equations for $m(\tau)^{r}, \lambda(t)$ given by (11) \& (12) equation in equation 2 and executing the aforementioned process and with the aid of few combined simplifications [5].

$\mathrm{a}^{r}=\frac{\mathrm{n}}{\left(1-\mathrm{e}^{-b t_{n}}\right)^{r}}$

$\mathrm{g}(\mathrm{b})=\frac{\mathrm{n}}{\mathrm{b}}+\sum_{i=1}^{n} \frac{(r-1) \cdot t_{i} \cdot e^{-b t_{i}}}{\left(1-e^{-b t_{i}}\right)}-\frac{r_{\cdot} t_{n} \cdot e^{-b t_{n}}}{\left(1-e^{\left.-b t_{n}\right)}\right.}-t_{i}$

$\mathbf{g}^{1}(\mathrm{~b})=\frac{r \cdot t_{n}{ }^{2} \cdot e^{-b t_{n}}}{\left(1-e^{\left.-b t_{n}\right)^{2}}\right.}-\frac{\mathrm{n}}{\mathrm{b}^{2}}-\sum_{i=1}^{n} \frac{(r-1) \cdot t_{i}{ }^{2} \cdot e^{-b t_{i}}}{\left(1-e^{-b t_{l}}\right)^{2}}$

We get closure form for variable ' $a$ ' in terms of ' $b$ '. Iterative Newton-Raphson method is used to solving the equations (13),(14),(15) in order to get the approximated a \& b value for the given set of failure data [7], [8].

\section{ESTIMATION OF PARAMETERS AND DECISION LINES USING ANOM}

Table 1 shows the sample dataset contains 104 weeks failure data [6], from that we calculated mean value function $m(t)$ from equation 3.

Table I: Failures Dataset [6].

\begin{tabular}{|c|c|c|c|c|c|}
\hline $\begin{array}{c}\text { Failure } \\
\text { No }\end{array}$ & $\begin{array}{c}\text { Time } \\
\text { Betwee } \\
\mathbf{n} \\
\text { Failures } \\
\text { (Hrs) }\end{array}$ & $\begin{array}{c}\text { Failure } \\
\text { No }\end{array}$ & $\begin{array}{c}\text { Time } \\
\text { Betwee } \\
\mathbf{n} \\
\text { Failures } \\
\text { (Hrs) }\end{array}$ & $\begin{array}{c}\text { Failure } \\
\text { No }\end{array}$ & $\begin{array}{c}\text { Time } \\
\text { Betwee } \\
\mathbf{n} \\
\text { Failures } \\
\text { (Hrs) }\end{array}$ \\
\hline 1 & 33 & 36 & 5 & 71 & 55 \\
\hline 2 & 9 & 37 & 66 & 72 & 409 \\
\hline 3 & 4 & 38 & 289 & 73 & 36 \\
\hline 4 & 66 & 39 & 3 & 74 & 15 \\
\hline 5 & 0.5 & 40 & 9 & 75 & 573 \\
\hline 6 & 18 & 41 & 12 & 76 & 583 \\
\hline 7 & 149 & 42 & 18 & 77 & 60 \\
\hline 8 & 14 & 43 & 9 & 78 & 19 \\
\hline 9 & 15 & 44 & 75 & 79 & 20 \\
\hline 10 & 50 & 45 & 15 & 80 & 79 \\
\hline 11 & 81 & 46 & 291 & 81 & 24 \\
\hline 12 & 34 & 47 & 212 & 82 & 540 \\
\hline 13 & 85 & 48 & 4 & 83 & 52 \\
\hline 14 & 54 & 49 & 5 & 84 & 1596 \\
\hline
\end{tabular}


Kotte Sandeep et al., International Journal of Emerging Trends in Engineering Research, 8(9), September 2020, 4894 - 4899

\begin{tabular}{|c|c|c|c|c|c|}
\hline 15 & 3 & 50 & 308 & 85 & 314 \\
\hline 16 & 15 & 51 & 269 & 86 & 1 \\
\hline 17 & 6 & 52 & 276 & 87 & 763 \\
\hline 18 & 8 & 53 & 1 & 88 & 10 \\
\hline 19 & 130 & 54 & 400 & 89 & 20 \\
\hline 20 & 19 & 55 & 294 & 90 & 144 \\
\hline 21 & 19 & 56 & 227 & 91 & 28 \\
\hline 22 & 112 & 57 & 118 & 92 & 56 \\
\hline 23 & 15 & 58 & 13 & 93 & 476 \\
\hline 24 & 16 & 59 & 47 & 94 & 65 \\
\hline 25 & 154 & 60 & 89 & 95 & 98 \\
\hline 26 & 50 & 61 & 242 & 96 & 884 \\
\hline 27 & 10 & 62 & 99 & 97 & 212 \\
\hline 28 & 2 & 63 & 607 & 98 & 287 \\
\hline 29 & 22 & 64 & 83 & 99 & 53 \\
\hline 30 & 53 & 65 & 2 & 100 & 3 \\
\hline 31 & 19 & 66 & 26 & 101 & 831 \\
\hline 32 & 58 & 67 & 586 & 102 & 43 \\
\hline 33 & 20 & 68 & 708 & 103 & 55 \\
\hline 34 & 3 & 69 & 6 & 104 & 109 \\
\hline 35 & 92 & 70 & 4 & & \\
\hline
\end{tabular}

From mean value $\mathrm{m}(\mathrm{t})$ we calculated upper decision line (UDL), central decision line (CDL), and lower decision line (LDL) using equation $16,17,18$.

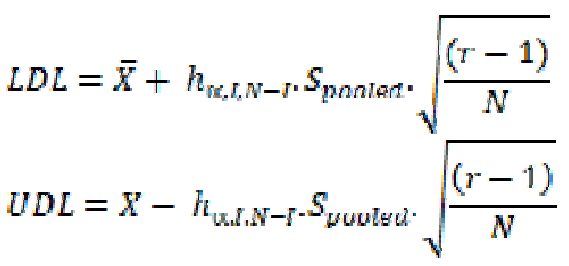

$C D L=\frac{L D L \mid U D L}{2}$

Where

$\bar{X}$ Represents the average of the individual means.

$S^{7}{ }_{\text {yvoled }}$ Represents the average of the individual variance.

$r$ represents the number of observations in each group

$\mathrm{N}$ number of observations in overall groups.

$\mathrm{H}$ value from table of critical value for analysis of means at an alpha level $=0.05$ using $r$ and N-r

The decision lines LDL, CDL, UDL and the parameters a and $\mathrm{b}$ are the deciding factors of the software assessing process.

Table II: parameter values and their control lines of $4^{\text {th }}, 5^{\text {th }}$ order

\begin{tabular}{|c|c|c|c|c|c|}
\hline Order & a & b & LDL & CDL & UDL \\
\hline 4 & 2.08493 & 0.199996 & 3.7235 & 5.0873 & 6.4511 \\
\hline 5 & 1.28753 & 0.199998 & 1.6955 & 3.1515 & 4.6075 \\
\hline 4 & 11.1343 & 0.190675 & 8.8553 & 9.9658 & 11.076 \\
\hline 5 & 6.87594 & 0.190675 & 5.0098 & 6.1612 & 7.3125 \\
\hline
\end{tabular}

Table II shows the value of $a$ and $b$, we calculated $a, b$, and decision lines using LPETM model and their results are given in row1 and row2. In row3 and row4 we obtained values using GO model. Table III shows the mean and standard deviation values of $4^{\text {th }}$ order LPETM model for Table I.

Table III: Mean and standard deviation values of 4th order LPETM model for Table I.

\begin{tabular}{|c|c|c|c|}
\hline Group & Count & Mean & Std \\
\hline 1 & 4 & 3.283125 & 1.955808 \\
\hline 2 & 4 & 3.327475 & 2.868705 \\
\hline 3 & 4 & 4.52595 & 1.282441 \\
\hline 4 & 4 & 3.76055 & 2.276067 \\
\hline 5 & 4 & 3.444475 & 2.3893 \\
\hline 6 & 4 & 3.931475 & 1.768464 \\
\hline 7 & 4 & 3.801025 & 2.884694 \\
\hline 8 & 4 & 4.29475 & 1.048203 \\
\hline 9 & 4 & 2.9907 & 2.36302 \\
\hline 10 & 4 & 4.288175 & 3.404345 \\
\hline 11 & 4 & 3.415125 & 1.633474 \\
\hline 12 & 4 & 5.121325 & 3.61172 \\
\hline 13 & 4 & 6.704325 & 3.508213 \\
\hline 14 & 4 & 6.518025 & 4.11941 \\
\hline 15 & 4 & 5.08685 & 1.776794 \\
\hline 16 & 4 & 7.6152 & 1.86161 \\
\hline 17 & 4 & 6.1992 & 4.732412 \\
\hline 18 & 4 & 4.314525 & 3.713483 \\
\hline 19 & 4 & 6.780075 & 3.678587 \\
\hline 20 & 4 & 4.463975 & 1.347337 \\
\hline 21 & 4 & 7.63695 & 3.925241 \\
\hline 22 & 4 & 5.4578 & 4.881345 \\
\hline 23 & 4 & 4.895625 & 1.649024 \\
\hline 24 & 4 & 8.0329 & 2.533689 \\
\hline 25 & 4 & 5.607775 & 3.415263 \\
\hline 26 & 4 & 6.772125 & 2.710676 \\
\hline & & & \\
\hline
\end{tabular}

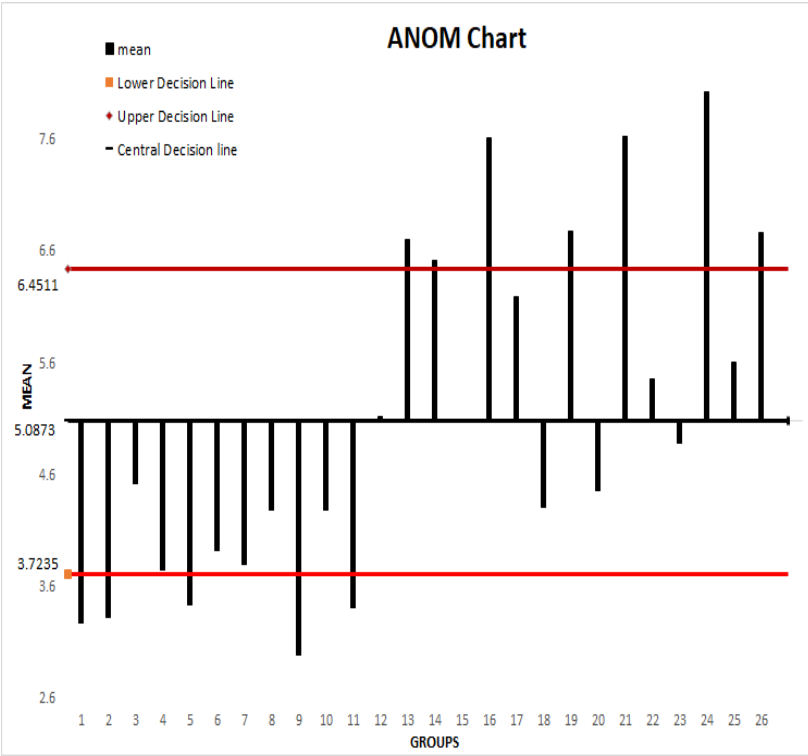

Figure 1: Analysis of Means using the $4^{\text {th }}$ order LPETM model for Table III. 
Kotte Sandeep et al., International Journal of Emerging Trends in Engineering Research, 8(9), September 2020, 4894 - 4899

Figure 1 shows the points 1, 2, 5, 9, 11 are below the decision line and points 13,14,16, 19, 21, 24, 26 are above the decision line using 4 th order statistics using LPETM. Table IV shows the mean and standard deviation values of $5^{\text {th }}$ order LPETM model for Table I.

Table IV: Mean and standard deviation values of $5^{\text {th }}$ order LPETM model for Table I.

\begin{tabular}{|c|c|c|c|}
\hline Group & Count & Mean & Std \\
\hline 1 & 5 & 1.64652 & 1.34896 \\
\hline 2 & 5 & 2.59378 & 1.158524 \\
\hline 3 & 5 & 2.76236 & 1.281684 \\
\hline 4 & 5 & 2.05868 & 1.286968 \\
\hline 5 & 5 & 2.83312 & 1.309848 \\
\hline 6 & 5 & 2.05242 & 1.154487 \\
\hline 7 & 5 & 2.3554 & 1.246766 \\
\hline 8 & 5 & 2.29698 & 1.982768 \\
\hline 9 & 5 & 2.04416 & 0.885554 \\
\hline 10 & 5 & 3.41686 & 2.373693 \\
\hline 11 & 5 & 4.30044 & 2.281702 \\
\hline 12 & 5 & 3.50118 & 1.245164 \\
\hline 13 & 5 & 3.84882 & 2.15336 \\
\hline 14 & 5 & 3.3304 & 2.747906 \\
\hline 15 & 5 & 3.89912 & 1.90288 \\
\hline 16 & 5 & 3.43296 & 1.675067 \\
\hline 17 & 5 & 4.84302 & 2.118345 \\
\hline 18 & 5 & 2.91476 & 2.499354 \\
\hline 19 & 5 & 3.76454 & 1.294404 \\
\hline 20 & 5 & 4.10448 & 2.322369 \\
\hline 21 & 4 & 4.1821 & 1.673948 \\
\hline
\end{tabular}

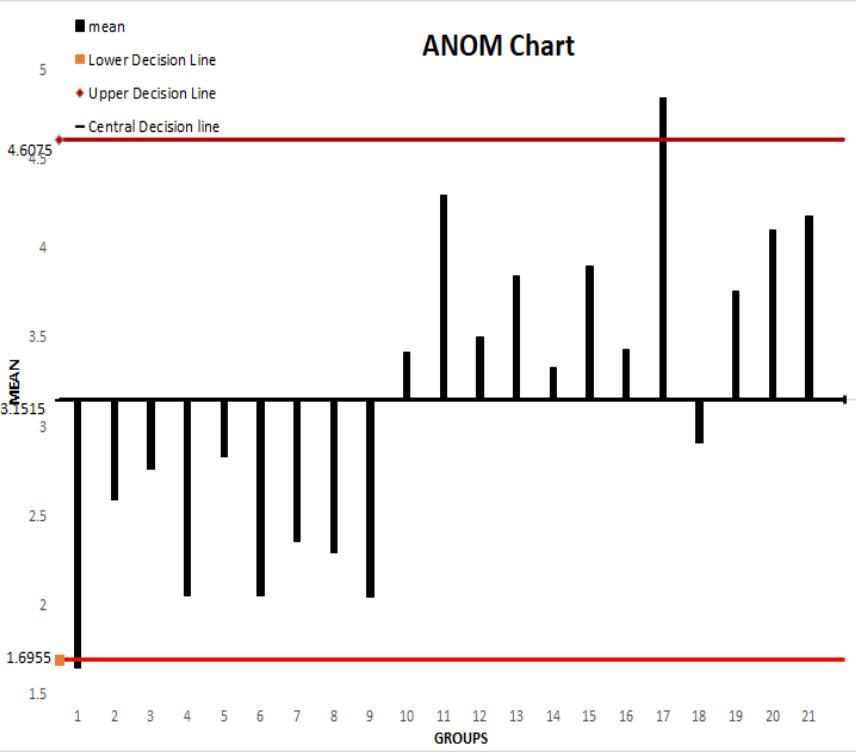

Figure 2: Analysis of Means using $5^{\text {th }}$ order LPETM model for Table IV.
Figure 2 shows, below the decision line and above the decision line points are 1 and 17 using 5th order statistics using LPETM. The results of mean values are shown in the Figure 1 and Figure 2, for the given failure dataset using $4^{\text {th }}$ order and $5^{\text {th }}$ order, respectively. Table $\mathrm{V}$ shows the mean and standard deviation values of $4^{\text {th }}$ order GO model for Table I.

Table V: Mean and standard deviation values of $4^{\text {th }}$ order go model for Table I.

\begin{tabular}{|c|c|c|c|}
\hline Group & Count & Mean & Std \\
\hline 1 & 4 & 9.330475 & 2.446765 \\
\hline 2 & 4 & 8.32105 & 4.882554 \\
\hline 3 & 4 & 10.97048 & 0.31588 \\
\hline 4 & 4 & 9.403875 & 3.050551 \\
\hline 5 & 4 & 9.567875 & 1.704639 \\
\hline 6 & 4 & 10.76893 & 0.281849 \\
\hline 7 & 4 & 8.8196 & 3.611349 \\
\hline 8 & 4 & 11.0179 & 0.144162 \\
\hline 9 & 4 & 8.429 & 3.092586 \\
\hline 10 & 4 & 9.062925 & 2.962695 \\
\hline 11 & 4 & 10.26155 & 0.887897 \\
\hline 12 & 4 & 9.6767 & 2.508406 \\
\hline 13 & 4 & 10.06148 & 2.14585 \\
\hline 14 & 4 & 8.834025 & 4.60075 \\
\hline 15 & 4 & 10.90063 & 0.466551 \\
\hline 16 & 4 & 11.1344 & 0 \\
\hline 17 & 4 & 9.2138 & 3.78918 \\
\hline 18 & 4 & 8.94935 & 2.61087 \\
\hline 19 & 4 & 10.97208 & 0.316898 \\
\hline 20 & 4 & 10.99853 & 0.158131 \\
\hline 21 & 4 & 11.10558 & 0.057251 \\
\hline 22 & 4 & 8.420475 & 4.394786 \\
\hline 23 & 4 & 11.0595 & 0.116676 \\
\hline 24 & 4 & 11.13437 & $5.00 \mathrm{E}-05$ \\
\hline 25 & 4 & 9.56325 & 3.141967 \\
\hline 26 & 4 & 11.13352 & 0.001495 \\
\hline & & & \\
\hline
\end{tabular}

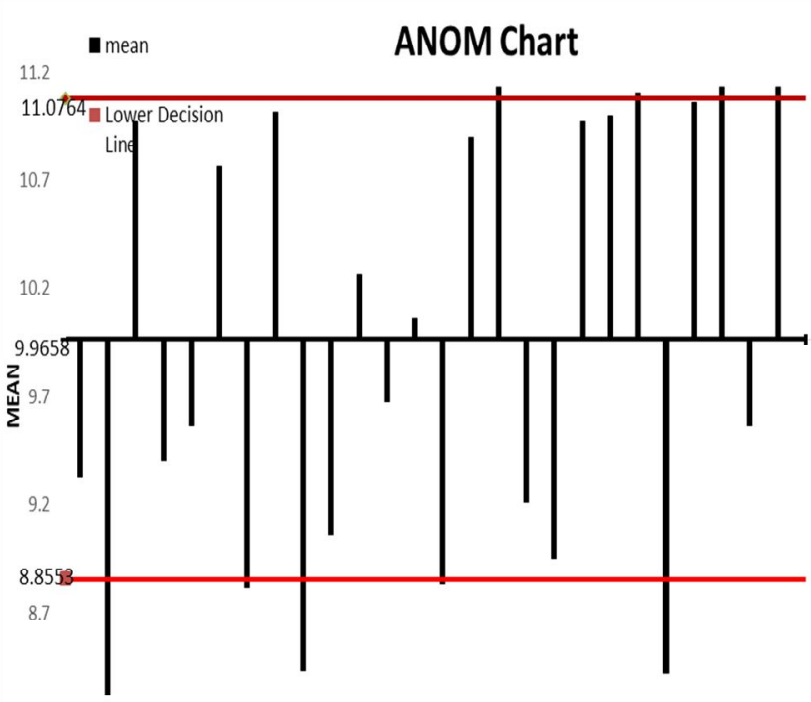

$\begin{array}{lllllllllllll}1 & 2 & 3 & 4 & 5 & 6 & 7 & 8 & 9 & 10 & 11 & 12 & 13 \\ \text { GROUPS } & 16 & 17 & 18 & 19 & 20 & 21 & 22 & 23 & 24 & 25 & 26\end{array}$

Figure 3:Analysis of Means using the $4^{\text {th }}$ order GO model for TableV. 
Kotte Sandeep et al., International Journal of Emerging Trends in Engineering Research, 8(9), September 2020, 4894 - 4899

Figure 3 shows the points 2, 7, 9, 14, 22 are below the decision line and points 16, 21, 24, 26 are above the decision line using 4 th order statistics using GO model. Table VI shows the mean and standard deviation values of $5^{\text {th }}$ order GO model for Table I.

Table VI: Mean and standard deviation values of $5^{\text {th }}$ order go model for Table I.

\begin{tabular}{|c|c|c|c|}
\hline Group & Count & Mean & Std \\
\hline 1 & 5 & 4.73464 & 2.643735 \\
\hline 2 & 5 & 6.65734 & 0.219367 \\
\hline 3 & 5 & 6.09764 & 1.734267 \\
\hline 4 & 5 & 6.02328 & 0.947043 \\
\hline 5 & 5 & 6.69538 & 0.181378 \\
\hline 6 & 5 & 5.71158 & 2.020305 \\
\hline 7 & 5 & 6.0327 & 1.700062 \\
\hline 8 & 5 & 5.32252 & 1.698942 \\
\hline 9 & 5 & 6.36598 & 0.479288 \\
\hline 10 & 5 & 5.70448 & 1.616063 \\
\hline 11 & 5 & 5.73946 & 2.541157 \\
\hline 12 & 5 & 6.76044 & 0.257729 \\
\hline 13 & 5 & 5.93674 & 2.100026 \\
\hline 14 & 5 & 5.78684 & 1.512681 \\
\hline 15 & 5 & 6.7957 & 0.175278 \\
\hline 16 & 5 & 6.80884 & 0.092516 \\
\hline 17 & 5 & 6.8617 & 0.031585 \\
\hline 18 & 5 & 5.50482 & 2.44717 \\
\hline 19 & 5 & 6.86928 & 0.014747 \\
\hline 20 & 5 & 6.09974 & 1.735435 \\
\hline 21 & 4 & 6.875375 & 0.000922 \\
\hline
\end{tabular}

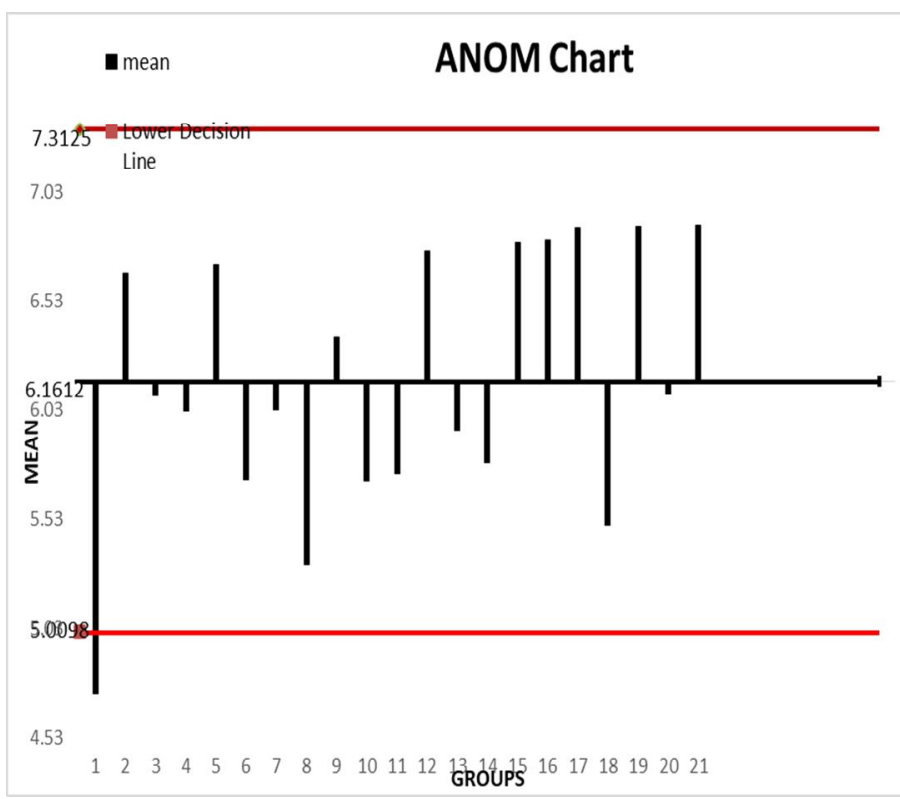

Figure 4: Analysis of Means using 5th order GO model for Table VI.
Figure 4 shows, below the decision line point is 1 using 5 th order statistics using the GO Model. The results of mean values are shown in the Figure 3 and Figure 4, for the given failure dataset using $4^{\text {th }}$ order and $5^{\text {th }}$ order respectively

\section{CONCLUSION}

Our proposed methods LPETM and GO models using order statistics approach has successfully identified the failures. When the decision lines are outside, this indicates that these means, or failures are statistically significant. When the decision lines are below LCL, it is likely that there are assignable causes leading to significant process and it should be investigated. The early detection of software failure with order statistics using ANOM will increase the software reliability. Hence, both proposed mechanisms are making the detection, either mechanism based on LPETM or GO model is preferable. We conclude that our proposed models give positive recommendation.

\section{REFERENCES}

1. K. Sandeep, R. Satya prasad, "Analysis of Theoretical Sampling Distributed using combined LPETM and ANOM subgrouping", Journal of Advanced Research in Dynamical and Control Systems ISSN: 1943-023X, Volume 11 Issue 1, Pages-467-471, May-2019.

2. $\quad$ K. Sandeep, R. Satya Prasad "Model Prediction using Correlation In Contrast With QQ-Plot”, International Journal of Innovative Technology and Exploring Engineering (ISSN: 2278-3075, Volume-8 Issue-9, July 2019.

3. K. S. Kumari, B. Amulya and R. S. Prasad, "Comparative study of Pareto Type II with HLD in assessing the software reliability with order statistics approach using SPC," 2014 International Conference on Circuits, Power and Computing Technologies [ICCPCT-2014], Nagercoil, 2014, pp. 1630-1636, doi: 10.1109/ICCPCT.2014.7054824.

4. R. S. Prasad and Y. Sangeetha, "Finding reliable software using SPRT based on Inflection S-Shaped Model: An order statistics approach," 2014 International Conference on Circuits, Power and Computing Technologies [ICCPCT-2014], Nagercoil, 2014, pp. 1554-1558, doi: 10.1109/ICCPCT.2014.7054984.

5. Krishna Mohan. G, Satya Prasad. R and Prof. Kantam. R.R.L. "Software Reliability Using SPC and Weibull Order Statistics", International Journal of Engineering Research and Applications (IJERA). Vol 1. Issue 4. pp[1486-1493], Nov-Dec, 2011.

6. Michael r. Lyu.,(1996a). "Handbook of software reliability engineering", Data Dictionary IEEE Computer Society and Mc.Graw-Hill, www.cse.cuhk.edu/ lyu/book/reliability/data/csr2.dat, csr3.dat, sys2.dat, sys3.dat, s2.dat 
7. Mekhala Sridevi Sameera, GangadharaRao Kancharla, R. Satya Prasad. Software reliability measurement using combined goel okumoto and anom perfect debugging model. Journal of Advanced Research in Dynamical and Control Systems ISSN: 1943-023X, Volume 11 Special Issue 11, Pages-780-787, 2019.

8. K. Sandeep, R. Satya prasad, "Analyzing Software Reliability with Order Statistics Approach using ANOM", Journal of Xidian University ISSN: 1001-2400, Volume 14 Issue 7, Pages-399-406, June-2020.

9. Satyaprasad, R. (2007). "Half Logistic Software Reliability Growth Model", Ph.D Thesis, Acharya Nagarjuna University, India. 